\title{
蛇行水路の外岸流速増大のモデル化 \\ に関する基礎的検討 \\ A BASIC STUDY ON THE MODELLING OF \\ TRANSVERSE INEQUALITY OF FLOW IN MEANDERING RIVER
}

\author{
劉 暢 1 ・石川忠晴 2 \\ Chang LIU and Tadaharu ISHIKAWA \\ 1学生会員 修(工) 東京工業大学大学院総合理工学研究科（广226-8502 横浜市緑区長津田4259番地） \\ 2 フェロー会員 工博 東京工業大学大学院総合理工学研究科（†226-8502 横浜市緑区長津田4259番地）
}

\begin{abstract}
Phase lag of stream meandering to channel curvature is the point of studies on river channel meandering. The stream meandering is generated by centrifugal force basically, but the effect of the force is usually considered by separating into two components; depth averaged component and component of deviation from the average. Existing 1-D theory of channel meandering only takes account of the former. This paper presents a new 1-D formulation of stream meandering in which the both components of the effect of centrifugal force is taken into account by extending a theory that was originally developed for secondary flow calculation. Results of numerical simulation by using the model agree fairly well with experimental data obtained in a meandering channel as well as in a single bending channel. This paper also discusses weight of two kind mechanism of stream meandering through numerical experiments under various hydraulic conditions of meandering channel flow.
\end{abstract}

Key Words : river meandering, transverse momentum shift, one dimensional formulation, weighted residual method

\section{1. はじめに}

沖積平野で河川流路が蛇行する現象は自然地理学 や河川工学の分野で古くから注目され1),2),3), 多くの 事例研究 4 (),5) や実験的研究6),7,8),9 が行われてきた。 そ の知見に基づいた現象の解析モデルも提案されてい る. 初期のモデルは蛇行発生機構に関するものであ $り^{10), 11), 12)}$, 微小振幅の交互砂州の不安定解析が主流 であった。 これらの研究では, 単列砂州の発達と蛇 行の発達が等価のものとして取り扱われている.

これに対してIkedaら $\left.{ }^{6}\right)$ は，蛇行河川の横断勾配が 水路軸曲率に比例するという経験的関係 ${ }^{3}$ を用い, 側岸の洗掘・堆積が岸沿いの流速の偏りに比例する という仮定のもとに, 一次元の蛇行流路発達モデル （bend equation）を提示した。このモデルは，方程 式の一次元化により蛇行の発展過程を追跡できると いう点で画期的であり, 観測データと概衫整合する 結果を与えている. その後, bend equationに基づく 蛇行発達特性の数学的検討が多数行われている ${ }^{7,9)}$.

ところでIkedaらは鉛直平均流に関する方程式の オーダ比較から一次元方程式を導いている. 一方, 湾曲水路では表層と底層の遠心力の差により断面内 に二次流の生じることが知られている ${ }^{10), 11), 122}$. 石川
$ら^{13)}$ は湾曲水路の二次流発達過程の一次元モデルを 組み立て，層流の場合について具体的に方程式系を 提示し，実験結果と比較している。このモデルは, 二次流の運動量輸送による外岸側での加速の程度を 定量的に算出できる. Ikedaらのモデルと石川らのモ デルは，ともに流心の側岸への偏りを表わす一次元 方程式だが，考慮しているメカニズムが異なってい る. ここでは便宜的に前者を 1 次シフトモデル，後 者を2次シフトモデルと呼ぶことにする.

実際には，1次シフトと2次シフトの両方の効果を 含めて側岸への流れの偏りを求める一次元方程式を 導出し, それぞれの影響の程度を調べた上で河川の 蛇行現象に適用寸ることが望ましいと考えられる. そこで本論文では，石川らの2次シフトモデルに1次 シフトの効果を加えた一次元モデルを作成し，石川 らの実験データと比較した上で，水理条件による両 要素の効果の重みを数值実験によって検討する。な お石川らの実験は層流について行われているので, 本研究の定式化も層流に対して行う. 水路湾曲部の 遠心力に起因する側岸流速の増加・減少の機構は層 流でも乱流でも基本的に同じである. そこで本研究 では粘性作用が明確な層流に対して原理的な検討を 行うものである. 


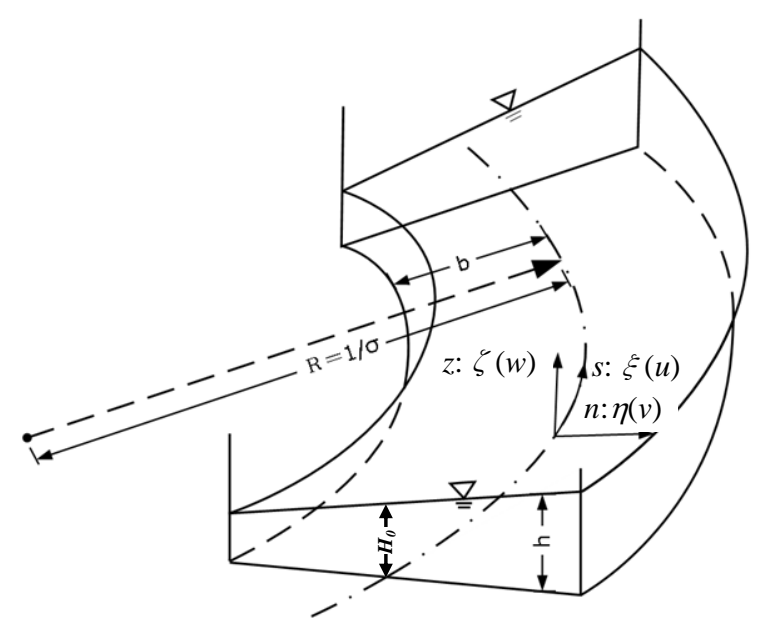

図-1 座標系

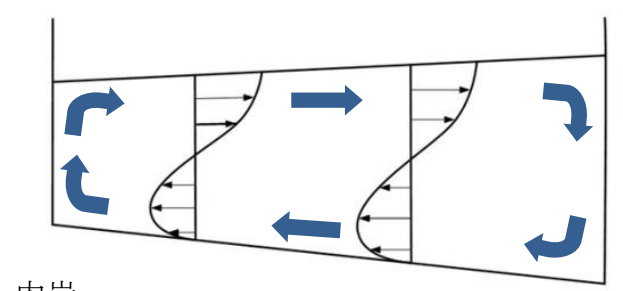

内岸

(a)

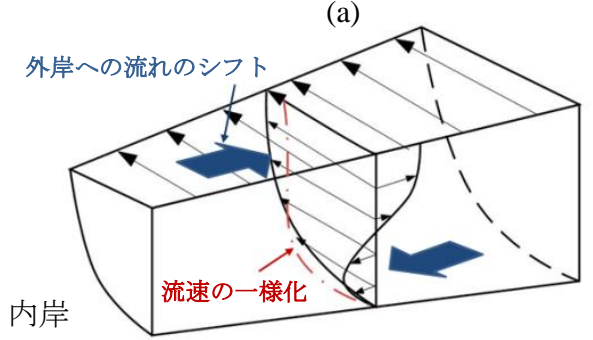

(b)

図-2 流れ構造の縦断変化

\section{2. モデル化}

\section{(1) 座標系}

本研究ではIkedaらと同様に台形断面の湾曲水路を 想定する。使用する座標系をまとめて図-1に示す. $(s, n, z)$ は有次元の座標で， $s$ は水路軸線に沿った下 流向きの距離, $n$ は水路軸に直交する右岸向きの距 離, $z$ は水路軸線上の河床を原点とした鉛直上向き の距離である。 $(\xi, \eta)$ は $(s, n)$ を水路半幅 $b て ゙$ 除した無 次元距離，らはzを水路軸線での水深 $h$ で除した無次 元高さである。また $(u, v, w)$ はそれぞれ $(s, n, z)$ 方向の 流速である。

\section{（2）石川・金のモデル}

本研究の基礎となる石川・金の手法を簡単にまと めておく. なお以降では便宜的に石川・金のモデル を旧モデル，本研究のモデルを新モデルという。彼 らは一定曲率の $180^{\circ}$ 単湾曲水路における層流の流速 分布を詳細に計測し，流れ構造の縦断変化を図-2
表-1 摂動パラメータの意味（旧モデル）

\begin{tabular}{|c|c|}
\hline 変数 & 変数の物理的意味 \\
\hline$\alpha_{1}(\xi)$ & 主流速の横断方向勾配 \\
\hline$\alpha_{2}(\xi)$ & 鉛直方向の流速一様化 \\
\hline$\alpha_{3}(\xi)$ & 二次流強度 \\
\hline
\end{tabular}

示すように説明した.

流速の大きい表層水は相対的に大きな遠心力を受 け外岸に輸送され, 底層水は内岸側に輸送される. その結果，外岸側流速は増加し，内岸側流速は減少 する。また外岸側の水は底層に潜り込み内岸側に輸 送され，内岸では表層に湧き上がり外岸に移動する。 その結果, 断面内で流速が一様化し, 遠心力の不均 一性が弱められるため二次流強度も減少して最終的 な安定状態が形成される。

以上の理解に基づき, 重み付き残差法に基づく “準三次元的一元モデル”が導出された。まず流速 分布を次のように仮定している.

$$
\begin{gathered}
u=u_{0}\left(1+\alpha_{1}(\xi) \eta\right)\left\{\phi(\zeta)+\alpha_{2} \psi(\zeta)\right\} \\
v=u_{0} \alpha_{3}(\xi) \psi(\zeta)
\end{gathered}
$$

ここに， $u_{0}$ は断面平均流速， $\alpha_{1}(\xi), \alpha_{2}(\xi), \alpha_{3}(\xi)$ は上 述の流れの機構に対応したパラメータで，それぞれ の意味は表-1 に示すとおりである。まため(ら)は式(3) で表される Hagen-Poiseuille の流速分布， (4)で表される流速偏差成分の鉛直分布である.

$$
\begin{gathered}
\phi(\zeta)=\frac{3}{2}\left(2 \zeta-\zeta^{2}\right) \\
\psi(\zeta)=6\left(\zeta-\frac{3}{2} \zeta^{2}+\frac{4}{3} \zeta^{3}\right)
\end{gathered}
$$

以上の式を曲線座標系の運動方程式に代入し，重 み付き残差法により断面積分し $\alpha_{1}(\xi), \alpha_{2}(\xi), \alpha_{3}(\xi)$ に 関する一次元連立微分方程式が導出された.

彼らの解析結果は，後に示すように，単湾曲水路 での実験結果とよく一致したが，蛇行水路での実験 結果との一致度は低かった。この原因は，式(2)にお いて全層的な横断流速（1次シフト）を考慮してい ないことによると考えられる。そこで本研究では1 次シフトを組み入れて解析方法を発展させ，実験結 果との一致度が向上するかどうかを調べた。

\section{（3） 1 次シフトを考慮したモデル化}

式(1)，(2)に対応する流速分布を式(5)，(6)のよう に仮定する。

$$
\begin{gathered}
u=u_{0}\left(1+\beta_{1}(\xi) \eta\right)\left\{\phi(\zeta)+\beta_{2} \psi(\zeta)\right\} \\
v=u_{0}\left\{\beta_{3}(\xi) \psi(\zeta)+\underline{\underline{\beta_{4}(\xi)\left(1-\eta^{2}\right) \phi(\zeta)}}\right\}
\end{gathered}
$$

旧モデルの未知パラメータ $\alpha_{\mathrm{i}}$ に対応する変数を新 モデルでは $\beta_{\mathrm{i}}$ と書く. その他の変数の定義は以前と 同じである。したがって式(5)は式(1)と内容的に同 じだが，式(6)では式(2)に対して_の部分を付け加 
表-2 㩒動パラメータの意味（新モデル）

\begin{tabular}{|c|c|}
\hline 変数 & 変数の物理的意味 \\
\hline$\beta_{1}(\xi)$ & 主流速の横断方向勾配 \\
\hline$\beta_{2}(\xi)$ & 鉙直方向の流速一様化 \\
\hline$\beta_{3}(\xi)$ & 二次流強度 \\
\hline$\beta_{4}(\xi)$ & 全層的な横断方向流速 \\
\hline$\beta_{5}(\xi)$ & 横断方向の水面勾配 \\
\hline
\end{tabular}

表-3 重み関数

\begin{tabular}{|c|c|c|c|}
\hline 元の方程式 & 対応変数 & 重み関数 & 一次元方程式 \\
\hline \multirow{2}{*}{ 式(8) } & $\beta_{1}(\xi)$ & $\eta$ & 式(12) \\
\cline { 2 - 4 } & $\beta_{2}(\xi)$ & $\psi(\zeta)$ & 式(13) \\
\hline \multirow{2}{*}{ 式(9) } & $\beta_{3}(\xi)$ & $\psi(\zeta)$ & 式(14) \\
\cline { 2 - 4 } & $\beta_{4}(\xi)$ & 1 & 式(15) \\
\hline 式(10) & $\beta_{5}(\xi)$ & $\eta$ & 式(16) \\
\hline
\end{tabular}

えている.この項は流向が水路軸からずれることを 考慮するもので, 1 次シフトの効果を表す. 横断方 向分布を $\left(1-\eta^{2}\right)$ とした理由は以下のとおりである. 1 次シフトにおいては，全層的なバランスから以下の $2 つ の$ 項が概ね釣り合わなければならない.

$$
\frac{\partial u}{\partial \xi} \sim \frac{\partial v}{\partial \eta}
$$

一方，式(5)において $u$ を $\eta$ の一次関数としている ので，上記のバランスを達成するには，vは $\eta$ につ

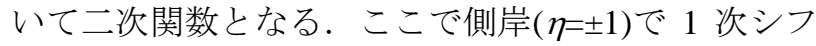
トによる $v$ をゼロとすると $\eta$ 関数形は $\left(1-\eta^{2}\right)$ となる。

さて、この項が $v$ に付加されたことにより，連続 条件が満足されるためには横断方向の水面勾配を考 慮する必要が生じる。そこで次式を設定する。

$$
h=H_{0}\left\{1+\beta_{5}(\xi) \eta\right\}
$$

式 $(5) \sim(7)$ に含まれる未知変数 $\beta_{\mathrm{i}}(\xi)$ の意味を表 -2 に示す. $\mathrm{i}=1 \sim 3$ では $\beta_{\mathrm{i}}(\xi)=\alpha_{\mathrm{i}}(\xi)$ である.

曲線座標系の運動方程式として式(8) (9)を，連続 式として式(10)を用いる ${ }^{14)}$.

$$
\begin{aligned}
& \frac{1}{(1+\sigma n)} u \frac{\partial u}{\partial s}+v \frac{\partial u}{\partial n}+w \frac{\partial u}{\partial z}+\frac{u v \sigma}{(1+\sigma n)} \\
& =-\frac{1}{(1+\sigma n)} g \frac{\partial h}{\partial s}+\frac{1}{(1+\sigma n)} g I_{s}+v \frac{\partial u^{2}}{\partial^{2} z} \\
& \frac{1}{(1+\sigma n)} u \frac{\partial v}{\partial s}+v \frac{\partial v}{\partial n}+w \frac{\partial v}{\partial z}+\frac{u^{2} \sigma}{(1+\sigma n)} \\
& =-g \frac{\partial h}{\partial n}+g I_{n}+v \frac{\partial v^{2}}{\partial^{2} z} \\
& \frac{1}{(1+\sigma n)} \frac{\partial u}{\partial s}+\frac{\partial v}{\partial n}+\frac{\partial w}{\partial z}+\frac{v \sigma}{(1+\sigma n)}=0
\end{aligned}
$$

ここで $\sigma$ は水路中心軸の曲率， $h$ は水深， $g$ は重力 加速度， $v$ は動粘性係数， $I_{\mathrm{s}}$ と $I_{\mathrm{n}}$ は $\mathrm{s}$ 方向および $n$ 方 向の水路勾配である。 $z$ 方向流速 $w$ は式(10)から次
式のように書かれる.

$$
w(\zeta)=h \int_{0}^{\varsigma} \frac{-1}{(1+\sigma n)} \frac{\partial u}{\partial s}-\frac{\partial v}{\partial n}-\frac{v \sigma}{(1+\sigma n)} d \zeta
$$

式(5) (7) と式(11)を式(8) (10)に代入し，表-3 に示 す重み関数を乗じて断面内で積分すると式(12) (16) を得る。

$$
\begin{aligned}
&\left(\frac{1}{3}-\frac{1}{5} b \sigma \beta_{1}\right)\left(\frac{6}{5}-\frac{2}{5} \beta_{2}+\frac{12}{35} \beta_{2}^{2}\right) \beta_{1}^{\prime} \\
&+\left(\frac{2}{3} \beta_{1}-\frac{1}{3} b \sigma-\frac{1}{5} b \sigma \beta_{2}^{2}\right)\left(-\frac{1}{5}+\frac{12}{35} \beta_{2}\right) \beta_{2}^{\prime}+ \\
& \frac{1}{3} g \frac{H_{0}}{u_{0}^{2}} \beta_{5}^{\prime}=2\left(-\frac{1}{5}+\frac{12}{35} \beta_{2}\right) \beta_{3} \\
&-\frac{2 b}{H_{0} \operatorname{Re}} \beta_{1}\left(1+2 \beta_{2}\right) \\
&-\frac{4}{15} b \sigma\left(\beta_{1}-b \sigma\right) \beta_{4}\left(\frac{6}{5}-\frac{1}{5} \beta_{2}\right) \\
&-\frac{2 b^{2} \sigma}{H_{0} \operatorname{Re}} \\
&-\frac{2}{3} b \sigma\left(\beta_{1}-b \sigma\right) \beta_{3}\left(-\frac{1}{5}+\frac{12}{35} \beta_{2}\right)
\end{aligned}
$$

$$
\begin{aligned}
&\left(\frac{1}{3} \beta_{1}-\frac{1}{5} b \sigma\right)\left(\frac{-57}{140}-\frac{82}{105} \beta_{2}-\frac{3}{35} \beta_{2}^{2}\right) \beta_{1}^{\prime} \\
&+\left(1-\frac{2}{3} b \sigma \beta_{1}+\frac{1}{3} \beta_{1}^{2}\right)\left(\frac{41}{105}-\frac{3}{35} \beta_{2}\right) \beta_{2}^{\prime} \\
&=\frac{4}{3} \beta_{1} \beta_{4}\left(-\frac{57}{140}+\frac{41}{105} \beta_{2}\right) \\
&-2 \beta_{1} \beta_{3}\left(\frac{41}{105}-\frac{3}{35} \beta_{2}\right) \\
&-\frac{4}{3} b \sigma\left(1-\frac{1}{5} b \sigma \beta_{1}\right) \beta_{4}\left(-\frac{57}{140}+\frac{41}{105} \beta_{2}\right) \\
&-2 b \sigma\left(1-\frac{1}{3} b \sigma \beta_{1}\right) \beta_{3}\left(\frac{41}{105}-\frac{3}{35} \beta_{2}\right) \\
&-\frac{72}{5} \frac{b}{H_{0} \operatorname{Re}} \beta_{2}
\end{aligned}
$$

$$
\begin{gathered}
\left(\frac{2}{3}-\frac{2}{15} b \sigma \beta_{1}\right)\left(\frac{-57}{140}+\frac{41}{105} \beta_{2}\right) \beta_{4}^{\prime} \\
+\left(1-\frac{1}{3} b \sigma \beta_{1}\right)\left(\frac{41}{105}-\frac{3}{35} \beta_{2}\right) \beta_{3}^{\prime} \\
=2 b \sigma\left(1-\frac{1}{3} b \sigma \beta_{1}+\frac{1}{3} \beta_{1}^{2}\right) \\
\cdot\left(\frac{-57}{140}-\frac{82}{105} \beta_{2}-\frac{3}{35} \beta_{2}^{2}\right) \\
-\frac{72}{5} \frac{b}{H_{0} \operatorname{Re}} \beta_{3}
\end{gathered}
$$




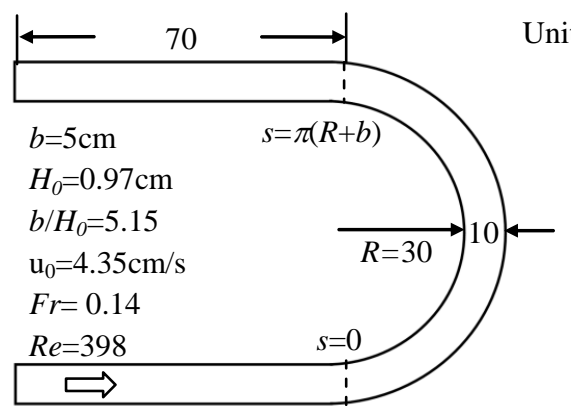

図-3＼cjkstart実験水路および条件（単湾曲水路）

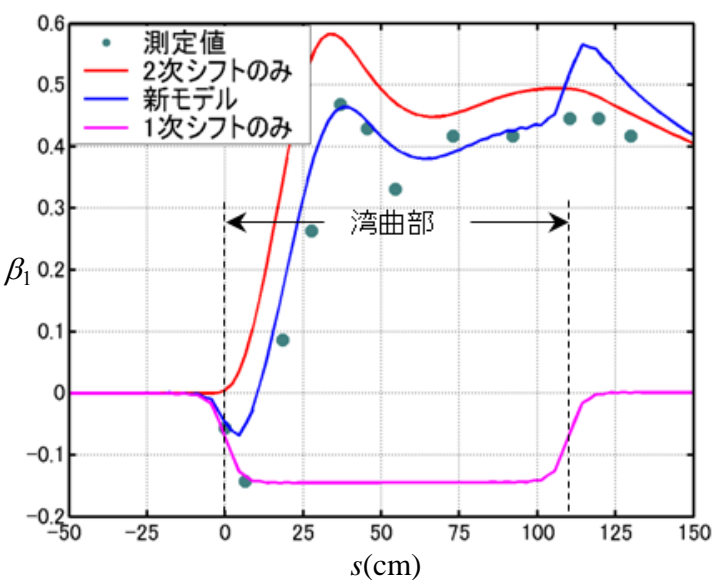

図-4＼cjkstart計算結果（単湾曲水路）

$$
\begin{aligned}
\left(\frac{2}{3}-\frac{2}{15} b \sigma \beta_{1}\right) & \left(\frac{6}{5}+\frac{1}{5} \beta_{2}\right) \beta_{4}^{\prime} \\
+\left(1-\frac{1}{3} b \sigma \beta_{1}\right) & \left(-\frac{1}{5}+\frac{12}{35} \beta_{2}\right) \beta_{3}^{\prime} \\
= & 2 b \sigma\left(1-\frac{1}{3} b \sigma \beta_{1}+\frac{1}{3} \beta_{1}^{2}\right) \\
\cdot & \left(\frac{-6}{5}-\frac{2}{5} \beta_{2}-\frac{12}{35} \beta_{2}^{2}\right) \\
- & 2 g \frac{H_{0}}{u_{0}^{2}} \beta_{5}-\frac{4 b}{H_{0} \operatorname{Re}}\left(\beta_{4}+3 \beta_{3}\right)
\end{aligned}
$$

$$
\begin{array}{r}
\left(1-\frac{3}{5} b \sigma \beta_{1}\right) \beta_{5}^{\prime}+\left(1-\frac{3}{5} b \sigma \beta_{5}\right) \beta_{1}^{\prime} \\
=4 \beta_{4}-\frac{4}{5} b \sigma \beta_{4}\left(\beta_{5}-b \sigma\right)
\end{array}
$$

項数が多いので複雑に見えるが, 計算過程は単純 な代数計算の反復であり, 結果は $\beta \mathrm{i}(\xi)$ に関する次の ような形の 5 元連立の一階微分方程式となっている.

$$
\begin{gathered}
\sum_{\mathrm{j}} \mathrm{f}_{\mathrm{j}}\left(\beta_{1}, \beta_{2}, \beta_{3}, \beta_{4}, \beta_{5}\right) \frac{d \beta_{j}}{d \xi} \\
=\mathrm{g}_{\mathrm{j}}\left(\beta_{1}, \beta_{2}, \beta_{3}, \beta_{4}, \beta_{5}\right)
\end{gathered}
$$

ここに $\mathrm{j}$ は 1 5 で，式(12) (16)に対応し， $f_{\mathrm{j}}$ と $g_{\mathrm{j}}$ は $\beta_{1}(\xi), \beta_{2}(\xi), \beta_{3}(\xi), \beta_{4}(\xi), \beta_{5}(\xi)$ の関数である. なお式 (15), (16)を省略し, $\beta_{4}(\xi)=0, \beta_{5}(\xi)=0$ とおくと旧モデ ルに対応した式となる。また式(12) (14)を省略し, $\beta_{1}(\xi)=0, \beta_{2}(\xi)=0, \beta_{3}(\xi)=0$ とおくと, 1 次シフトのみ
Unit: $\mathrm{cm}$

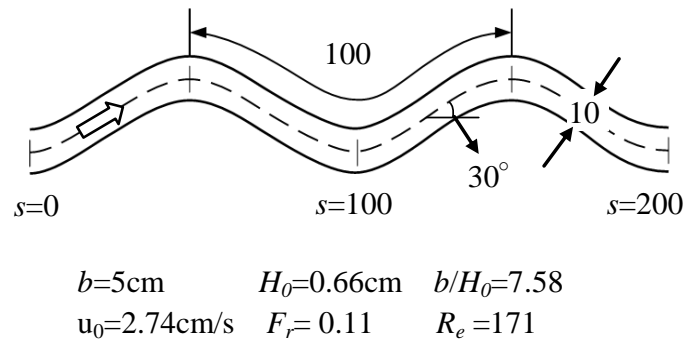

図-5＼cjkstart実験水路および条件（蛇行水路）

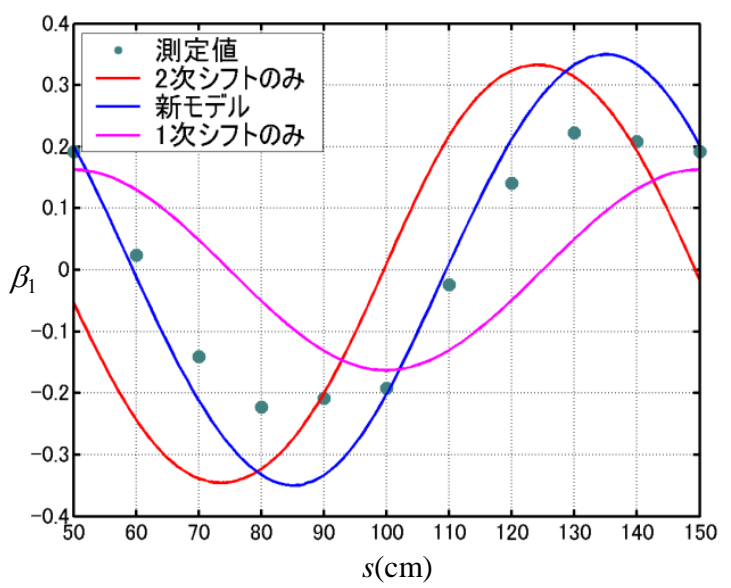

図-6 計算結果（蛇行水路）

を考慮した式となる。

\section{（4）数值解法}

旧モデルでは水深 $h$ に関する変数が含まれていな かったので境界条件は全て上流側で与えられ，微分 方程式は Runge-Kutta 法により積分された。新モ デルでは流速に関する変数 $\beta_{1}(\xi) \sim \beta_{4}(\xi)$ の境界条件は 上流側で，水深に関する変数 $\beta_{5}(\xi)$ は下流側で与える 必要がある。そこで単湾曲水路に対しては，前者を 湾曲開始点より十分上流( $\xi=-10.9)$ において，後者を 湾曲終了点の十分下流( $\xi=65.4)$ で 0 とした。 また蛇 行水路では全てを周期境界条件とした。 以上の設定 のもとで，線形三角形要素を用いた一次元有限要素 法を適用し陰形式で解いた。非線形項については逐 次代入により緩和係数 0.6 で反復収束させた.

\section{3. 水路実験との比較}

本節では石川らの実験の条件で数值計算を行い, モデルの妥当性を検討する. なお彼らの実験水路で は、横断方向の河床勾配 $I_{n}$ はゼロである.

\section{(1) 単湾曲水路}

図-3 に示す単湾曲水路の条件 ${ }^{13)}$ での横断方向流 速勾配 $\beta_{1}(\xi)$ の計算結果を，実験結果とともに図-4 に示す。図中には 2 次シフトのみを考慮した旧モデ ルと，1 次シフトのみを考慮した場合の計算結果も 示している.プラスの值が外岸側への流心のシフト を表している。 


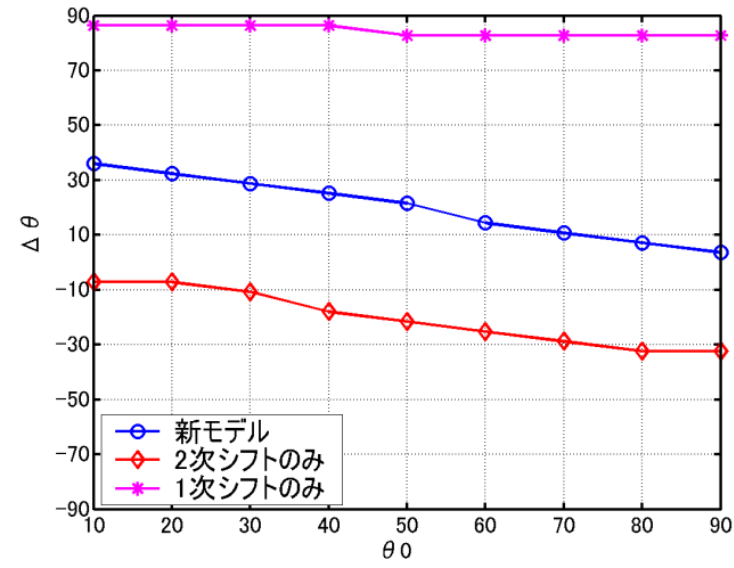

図-7＼cjkstart流心蛇行の位相遅れに対する蛇行度の影響

旧モデルと新モデルの解は概ね類似した傾向を示 寸が, 次の点で違いがみられる. 旧モデルでは湾曲 入口から単調に増加寸るのに対して, 新モデルでは 実験結果と同様に内岸側に一旦シフトしてから外岸 側にシフトする。 これは, 湾曲流入部で内岸側の水 位が低下し内岸で加速が生じるからである。この運 動は全層的流れ（1 次シフト）であり， 2 次シフト のみを考慮する旧モデルでは表現できない，その後， 二次流が発達すると 2 次シフトが支配的になり流心 は外岸側に移動する。一方, 1 次シフトのみのモデ ルは湾曲流入部での変化をよく表現するが，その後 の二次流発生に伴う変化を表現できず，終始内岸側 の流速が大きい。 なお湾曲出口では, 入口と同じ理 由で新モデルは局所的な外岸側への流心のシフトを 示す. 実験データでも同じ位置で值が増加するが, 計算ほど大きな值にはなっていない。この原因は不 明である。

\section{（2）蛇行水路}

図-5に示寸蛇行水路の実験条件での横断方向流 速勾配 $\beta_{1}(\xi)$ の計算結果を, 実験結果とともに図-6 に示寸. なお水路軸線は波長 $100 \mathrm{~cm}$ 最大振れ角 $30^{\circ}$ の sine generated curve である. 図-5には 2 次シフト のみを考慮した場合と, 1 次シフトのみを考慮した 場合の計算結果も示している.

旧モデルと実験結果の間には明らかな位相のずれ が見られる。これは 1 次シフトを考慮に入れていな いことによる. 一方， 1 次シフトのみのモデルも位 相のずれが大きい。これに対して新モデルと実験 データの位相はほぼ一致している。振幅が実験結果 よりやや小さいが, これは側壁での摩擦の影響を取 り込んでいないことによると思われる。同実験では [水路幅/水深]が 10 であり, 側壁摩擦の影響が若干 生じていると考えられる.

\section{4. 数値実験による検討}

前節の検討において，本研究における一次元的定 式化が水路の湾曲や蛇行に伴う流心の側岸への偏り

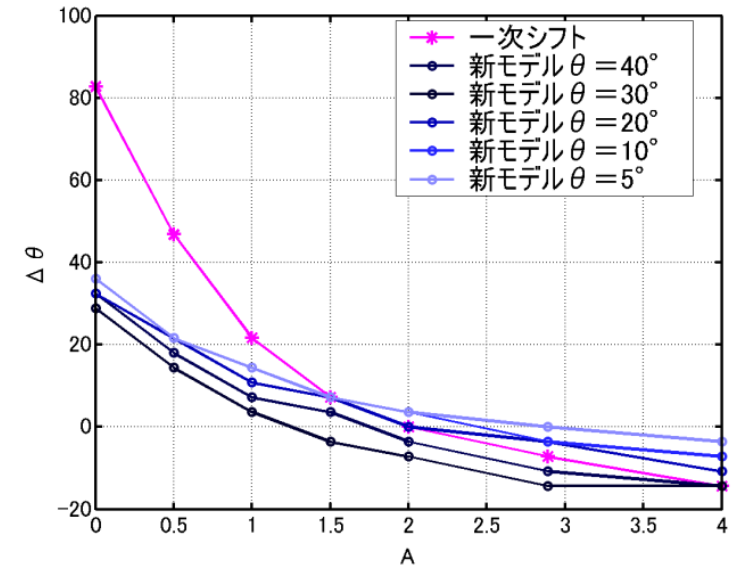

図-8＼cjkstart流心蛇行の位相遅れに対する 河床横断勾配の影響

を概ね適正に表現できることがわかった。そこで 本節では蛇行水路の諸元を規則的に変化させた数值 実験により, 流心の偏りに対する 1 次シフトと 2 次 シフトの効き方を検討する.

\section{（1）蛇行度の影響}

図-5に示した水路の最大振れ角を系統的に変化さ せて計算を行い, 水路軸の蛇行と流心の偏りとの位 相差を求めた。蛇行発達の理論においては, この位 相差が重要な役割を果たす。なお両者の位相差は相 互相関係数が最大となる位相として求めた。 その結 果を, 1次シフトのみの場合, 2次シフトのみの場合 とともに図-7に示す. 横軸は蛇行の最大振れ角 $\theta_{0}$ で ある。

1次シフトの場合は常に $90^{\circ}$ 近辺にある.これは, 式(9)の左辺第4項を外力とする横断方向のセイシュ の基本的性質であり, 蛇行する平坦水路の1次シフ トの特徴である. 2次シフトのみの場合は, 図-6に も示したように，位相が実際より早くなる，両方を 考慮する新モデルでは，それらの中間的位相となる。 蛇行度が小さい場合, 流心の偏りは水路軸の蛇行に 対して位相遅れを持つので, Bend equationで仮定さ れているように流心の偏りと側岸浸食が比例すると すれば蛇行波形は下流に伝播することになる。一方， 蛇行度が大きくなると位相差はゼロに近づくので, 蛇行の下流への伝播は遅くなると考えられる.

\section{（2）河床横断勾配の影響}

以上は全て水路床が平坦な場合の結果であった. しかし実際の蛇行河川では河床に横断勾配が存在し， このために 1 次シフトの影響が大きくなると考えら れる. Ikeda \& Parker ${ }^{6}$ は Engelund $^{3}$ が提示した経験 式(18)に基づき横断勾配を仮定し Bend equation を誘 導している.

$$
\frac{\mathrm{d} \eta^{\prime}}{H_{0}}=A \sigma n
$$

ここに $\eta^{\prime}$ は横断平均河床からの河床高, $H_{0}$ は水路軸 線上の水深, $\sigma$ は水路の曲率, $n$ は横方向の座標, $A$ 
は定数である.これより式(9)の横断河床勾配 $I_{\mathrm{n}}$ は以 下のように書かれる.

$$
I_{\mathrm{n}}=-A \sigma H_{0}
$$

$A$ の值として, Engelund $^{3)}$, 吉川ら ${ }^{12)}$ は 4.0 を推奨 している. 一方, Ikeda \& Parker $^{6}$ は 2.89 を推奨して いる。式(19)からわかるように，Aの值を経験的に 推定する場合には代表水深 $H_{0}$ の定め方が問題とな るが，それは代表流量の定義に依存するので，必ず しも一つの值に定まらない可能性もある. 式(18)の 重要な点は河床横断勾配が水路軸の曲率 $\sigma$ に比例す るということである。 そこで，ここでは $A=0 \sim 4$ の 間で種々設定し, モデルの応答を調べた。

図-5 に示した水路形状で, 式(19)に従って $I_{n}$ を与 えて計算を行い, 水路軸の蛇行と流心の偏りとの位 相差を求めた。係数 $A$ を横軸にとり, 本モデルの計 算結果と 1 次シフトのみのモデルでの計算結果を, いくつかの $\theta_{0}$ (蛇行度) について図-8に示寸. 一次 シフトのみのモデルの場合（ピンク）, 蛇行度によ らず 1 本の曲線となり， 2 次シフトが加わると蛇行 度によって結果が異なってくる。

$A$ が小さい場合には両者の開きは大きいが，ある 程度 $A$ が大きくなると一致してくる傾向がみられる. したがって実際の蛇行河川で大きな河床横断勾配が 生じている場合, 河岸への流心の偏りを 1 次シフト のみのモデルでも十分算定できる可能性がある。た だし平坦床 $(A=0)$ から河床横断勾配が形成される過 程では 2 次シフトが重要となるので, 蛇行発達の全 過程を追跡する場合には 2 次シフトを無視できるわ けではない。

\section{5. おわりに}

本研究では，石川・金の二次流モデルを改良する ことにより, 流心の側岸への偏りに関する一次元方 程式の枠組みを提出した。 また層流の流速分布を代 入して具体的な式展開を行い実験結果と比較して妥 当性を検証した後, パラメータを変化させた数值実 験でモデルの応答特性を調べた。

主な結論は以下のとおりである.

1） 1 次シフトと 2 次シフトを考慮することにより, 単湾曲水路および蛇行水路における側岸への流 心の偏りの算定精度がかなり向上した。

2) 水平床水路での層流条件では, 1 次シフトのみ の計算結果は実験結果から大きくずれていた. また蛇行度が大きくなるほど誤差は増大した。

3）しかし，横断河床勾配がある程度大きくなると (式(18)で $A>2$ ), 1 次シフトのみを考慮した計 算でも流心の偏りを十分算定できる可能性があ る.

なお, 本研究では抵抗則の明確な層流について式 展開を行い実駼結果と比較したが，同じ枠組みにお いて式(1)，(2)の流速分布関数 $\phi(\zeta)$ と $\psi(\zeta)$ を変更すれ ば，乱流についても同様の式を導くことができる. その際, 層流に比較して乱流の流速鉛直分布は均一
なので，二次流が相対的に弱くなると予想される. したがって上記の結論の 3)は乱流の場合においても 成立すると予想される。 ただし, 蛇行の発生初期に おいて河床横断勾配が形成される過程では 2 次シフ 卜の影響が当然大きいので, 実際的な状況において 1 次シフトと 2 次シフトの効果をさらに検討する必 要がある. 本研究ではその基礎となる一次元方程式 系の枠組みを提示した。 今後は同様の式展開を乱流 についても行い, さらに河床横断勾配の時間発展も 含めた一次元方程式系を導きたいと考えている.

\section{参考文献}

1) L.B. Leopold and M.G. Wolman: River Meanders, Geol. Soc. Am. Bull, Vol.71, pp. 769-794, 1960.

2) Bagnold, R.A.: Some aspect of the shape of river meanders, U.S. Geo. Surv. Prof. Pap., Vol. 282-E, pp.135-144, 1960.

3) Engelund, F.: Flow and Bed Topography in Channel Bends, J. Hydraul. Div., Proc. ASCE, Vol.100, pp.1631-1648, 1974.

4) Bates, R. E.: Geographic history of the Kickapoo region, Wisconsin, Geol. Soc. America Bull, Vol.50, pp. 819-879, 1939.

5) Hikin, E.J. and Nanson, G.G.: The Character of Channel Migration on the Beatton River, Northeast British Columbia, Canada. Geol. Soc. Am. Bull, Vol.86, pp. 487-494, 1975.

6) Ikeda, S. and Parker, G.: Bend theory of river meanders, vol 1. Linear development, J.Fluid Mech, Vol.112, pp.363-377, 1981.

7) Gary Parker and Edmund D. Andrews: On the time development of meander bends, J. Fluid Mech, Vol. 162, pp. 139-156, 1986.

8) da Silva, A.M.F, Tarek EI-Tahawy, and William D.Tape: Variation of Flow Pattern with Sinuosity in Sine-Generated Meandering Streams, J.Hydraul. Eng., Vol.132, No.10, pp.1003-1014, 2006.

9) Emma K. Raven, Rob Ferguson and Stuart N. Lane: A coupled sediment routing and lateral migration model for gravel-bed rivers, J. Hydrol. Process, Vol. 25, pp.18871898, 2011.

10) 池田駿介: 移動床河川の湾曲部における二次流と動的 横断平衡河床について, 土木学会論文報告集, No. 229, pp.55-65, 1974.

11) Jinhong Zhou, Howard H. C.: A model for phase lag of secondary flow in river meanders, J. Hydrol, Vol.146 pp. 73-88, 1993.

12) 吉川秀夫, 池田駿介: 湾曲水路の河床変化について, 土木学会論文報告集, No. 251, pp.65-75, 1976.

13) 石川忠晴, 金舜範: 湾曲部の二次流に関する基礎的研 究, 土木学会論文集, No.375/II-6, pp.143-149, 1986.

14) 吉田圭介, 石川忠晴: 円筒座標系CIP-Soroban法と境界 適合座標法を組み合わせた蛇行河川の準三次元計算法, 水工学論文集, No.52, pp.997-1002, 2008.

(2011. 9. 30受付) 